\title{
Food Integrity Climate in Food Businesses: Conceptualization, Development, and Validation of a Self-Assessment Tool
}

\author{
Waeel Salih Alrobaish ${ }^{1, *(\mathbb{D})}$, Liesbeth Jacxsens ${ }^{1}$, Pieternel A Luning ${ }^{2}$ and Peter Vlerick ${ }^{3}(\mathbb{D}$ \\ 1 Department of Food Technology, Safety and Health, Faculty of Bioscience Engineering, Ghent University, \\ Coupure Links 653, 9000 Ghent, Belgium; liesbeth.jacxsens@ugent.be \\ 2 Food Quality and Design Group, Wageningen University and Research, P.O. Box 17/Bode 30, \\ 6700 AA Wageningen, The Netherlands; pieternel.luning@wur.nl \\ 3 Department of Work, Organization and Society, Faculty of Psychology and Educational Sciences, \\ Ghent University, Henri Dunantlaan 2, 9000 Ghent, Belgium; peter.vlerick@UGent.be \\ * Correspondence: waeel.alrobaish@ugent.be; Tel.: +32-46-097-5522
}

Citation: Alrobaish, W.S.; Jacxsens, L.; Luning, P.A; Vlerick, P. Food Integrity Climate in Food Businesses: Conceptualization, Development, and Validation of a Self-Assessment Tool. Foods 2021, 10, 1302. https:// doi.org/10.3390/foods10061302

Academic Editor: Federico Marini

Received: 20 May 2021

Accepted: 3 June 2021

Published: 6 June 2021

Publisher's Note: MDPI stays neutral with regard to jurisdictional claims in published maps and institutional affiliations.

Copyright: (c) 2021 by the authors. Licensee MDPI, Basel, Switzerland. This article is an open access article distributed under the terms and conditions of the Creative Commons Attribution (CC BY) license (https:// creativecommons.org/licenses/by/ $4.0 /$ )

\begin{abstract}
Current scientific research and industry guidelines focus on food safety, aiming to reduce unintentional food contaminations through technological and managerial measures. Due to the deceptive nature of food fraud, the fight to prevent intentional food adulteration and counterfeiting threats requires an approach that goes beyond the common food safety-based strategies and falls into the sphere of food integrity. With food integrity being an emerging discipline, a definition was proposed and the concept of food integrity climate was introduced. A food integrity climate (FIC) self-assessment tool in the form of a questionnaire, with twenty indicators and a five-point Likert rating scale was developed, expert-validated, and tested in practice in a large-scale meat distribution company. The questionnaire was designed to measure the performance level of food integrity in food businesses along the supply chain through managers' and operators' perceptions. Minor but interesting differences were found in the food integrity climate perceived between managers and operators as well as among the company's affiliates. The tool helps food businesses to get a deeper insight on the human dimension behind food integrity through the assessment of five climate components in relation to four food integrity elements, identifying strengths and weaknesses regarding a company's food integrity climate.
\end{abstract}

Keywords: food integrity; food integrity climate; food safety climate; self-assessment tool

\section{Introduction}

Scientific research, industry standards, and (inter)national regulations focus primarily on food safety, aiming to reduce unintentional food contaminations through analytical methods, technological interventions, implementation of food safety management systems, certifications, and audits [1-3]. These measures are not specifically designed for food fraud control, mitigation, and prevention, since they do not consider the intentional contamination and economically motivated driven behavior leading to unacceptable risks [4-6]. Due to the intentional and deceptive nature of food fraud, the fight to reduce and prevent deliberate food adulteration and counterfeiting threats requires an approach that goes beyond the common food safety-based strategies and falls into the sphere of food integrity [7-10].

The concept of food integrity goes beyond the mere food safety-related concerns, comprising in its notion all the aspects of food processing, handling, and monitoring occurring along the food supply chain. As two opposed faces of the same coin, food integrity and food fraud consider not only technical and managerial factors but also the human dimension involved in the actual execution of processes $[5,8,11]$.

Few scientific studies have been conducted on the theoretical conceptualization of food integrity and its defining elements [5,8,11-15]. However, as food integrity is an emerging discipline, its concept remains still unclear and no unanimous definition exists yet. A deeper 
insight into the specific role of the human factor in food integrity still needs to be addressed. Recent food safety research revealed that the techno-managerial approach towards food safety should be complemented by a human route, as expressed by operators' perceptions of the organizations' food safety climate [16]. Manning (2020) [10] also advocates the importance and the need of developing tools to assist food companies to evolve from a compliance-based organizational food safety climate to an ethically strong organizational climate that focuses on the more comprehensive concept of integrity. Moreover, Ling and Wahab (2020) [6] argue that the implementation of food safety management systems based on prerequisites programs and HACCP principles alone is insufficient since it does not prevent deliberate contamination as it is designed for food safety hazard control rather than food integrity.

This paper proposes a definition of food integrity and, in consideration of the human dimension involved within the organizations' decision-making processes, introduces the concept of a food integrity climate. The development, expert validation, and testing in practice of a food integrity climate (FIC) self-assessment tool, designed to specifically measure the food integrity performance level in food companies along the supply chain through managers' and operators' perceptions, is detailed. Implications concerning food integrity management for food businesses are derived from the application of the FIC tool in a large-scale meat distribution company.

\section{Materials and Methods}

\subsection{Defining Food Integrity}

Based on a literature study on the domain of food integrity and related concepts, such as food safety, food quality, food authenticity, food defense and food fraud, as well as discussion with three subject-matter academic experts operating in Belgium and the Netherlands (an expert on food safety management, an expert on work and occupational health psychology, and an expert on food quality and design), a definition of food integrity is proposed and a schematic representation of the nature and interconnection of food integrity and food fraud elements is presented.

\subsection{Conceptualizing Food Integrity Climate}

Based on a literature study in the domain of organizational climate and food integrity, as well as discussion with three subject-matter academic experts operating in Belgium and the Netherlands (an expert on food safety management, an expert on work and occupational health psychology, and an expert on food quality and design), the concept of a food integrity climate is introduced along with its definition and key elements. A conceptual model of food integrity climate is also presented.

\subsection{Development of a Food Integrity Climate Self-Assessment Tool}

Based on the proposed food integrity climate definition and elements, a self-assessment tool was developed to assess the food integrity performance level as perceived by employees of food companies along the supply chain. Indicators were formulated based on literature reviews on relevant subjects such as food fraud, food safety climate and food integrity, as well as following discussion with three subject-matter academic experts operating in Belgium and the Netherlands (an expert on food safety management, an expert on work and occupational health psychology, and an expert on food quality and design).

\subsection{Expert Validation of the Food Integrity Climate Self-Assessment Tool}

To examine the validity of the developed FIC tool, a balanced panel of twelve experts, not involved in the development of the tool, with expertise in food safety and quality management at the academic level (six experts) and at the industry level (six experts), operating in Belgium, Italy, and Saudi Arabia, were asked through an online survey to evaluate the relevance and the importance of each indicator of the tool. The academic experts were selected based on their knowledge in constructing self-assessment tools for the 
evaluation of food quality, food authenticity, and food safety management systems within food organizations, while the industry experts were chosen based on their experience in managing food safety and food integrity-related issues in food companies.

Inspired by the method adopted by De Boeck et al. (2015) [16], each expert had to indicate whether they considered the twenty indicators of the preliminary version of the tool relevant ("Does the indicator add to the understanding of food integrity climate?") by means of a yes/no answer. Further, they had to rate the importance or validity of each indicator ("Does the indicator measure an important aspect of food integrity climate?") by means of a four-point Likert answer scale from very important (1), important (2), somewhat important (3), to not important (4). Experts were also given the possibility to write open suggestions to improve the comprehensibility of each indicator.

If $50 \%$ or less of the responding experts did not consider the indicator relevant, this was deleted. For the importance rating, the median, mean, and standard deviation of each indicator were calculated. Indicators were considered valid if they were rated overall from very important (1) to somewhat important (3). Finally, based on the open suggestions, indicators could be made more understandable and meaningful, or new indicators could be added.

\subsection{Testing in Practice of the Food Integrity Climate Self-Assessment Tool}

To test the feasibility of the FIC tool when applied in a food business context, a single testing of the FIC tool was performed in eight randomly selected affiliates of a large-scale meat distribution company with over three hundred branches and almost four thousand employees in Belgium and Luxembourg. All operators $(n=34)$ in the eight affiliates, including chefs, assistants, and salesmen, and their management $(n=18)$, including general director, quality manager, sales managers, and managers in charge of the affiliates, were invited to participate in the study. The researchers personally handed out a printed version of the FIC tool in Dutch to the participants. A cover letter was attached to the questionnaire explaining the scientific purpose of the study and stated that, although participation was not mandatory, filling in the survey implied consent and that confidentiality was guaranteed. The researchers' contact details were also provided. Upon filling in, the participants were asked to send back the questionnaires using the internal post service. Informed consent was obtained from the board of directors of the participating company to conduct the study and publish anonymously the results.

Inspired by the method adopted by De Boeck et al. (2015) [16], the research objectives of the study were to (1) assess the company's food integrity climate, (2) compare how this is perceived among the eight different affiliates, (3) evaluate if there is a difference in perception between management and operators, and (4) estimate statistically the reliability of the tool. To achieve the first three research objectives, the mean score of the overall food integrity climate (calculated over the twenty indicators), the mean score of each food integrity element (calculated over the five indicators per element), the mean score of each climate component (calculated over the four indicators per component), and the mean score of each food integrity climate indicator was calculated for the total sample, for the management, each affiliated butcher shop, and all affiliates' operators. Finally, the Cronbach's alpha of the questionnaire was calculated to assess the reliability and internal consistency of the tool. Data processing was executed using IBM SPSS version 26.

\section{Results and Discussion}

\subsection{Defining Food Integrity}

Food integrity has been defined by Elliott (2014) [13] as the condition of a food product to be safe, of quality, authentic, traceable, and genuine in all its aspects, whose nature has not been altered or modified and whose claims are honest and meet consumer expectations. Accordingly, it is agreed that food integrity is a multidisciplinary and multidimensional concept, covering all aspects of the food chain, from producer to consumer, and capturing 
all aspects of food production, such as the way the food has been sourced, produced, and distributed $[6,12,13,17]$.

Manning (2016) [8] argued that food integrity includes four elements that need to be considered to safeguard integrity in the food supply chain: product integrity, process integrity, people integrity, and data integrity, defined in Figure 1 (left side).

Similarly, Ali et al. (2017) [15] suggested that food integrity comprehends the whole food supply chain, involving particularly four distinctive dimensions: (1) raw material integrity, at the supplier stage, meaning safe, pure, quality ingredients with authentic and verifiable origins; (2) production integrity, at the manufacturer stage, referring to effective internal control system, quality assurance, manufacturing strategies, and procedures; (3) service integrity, at the food service stage, regarding controlled franchises, outsourcing activities and human resources involved by a food company as third party operators; and (4) information integrity, at the consumer stage, concerning truthful, honest, and appropriate data conveyed to the consumers through the product labeling and company logo.

Other attributes recurring in most food integrity definitions relate to healthy, tasty, and nutritional product ingredients $[5,12]$ that are sustainable in nature, considerate of animal welfare, free of child labor, and favor trades with developing countries [12]. This creates consumer trust and brand integrity [14], by safeguarding the food supply chain from fraud risks [11] and considering cultural matters in the processing and handling of food [5]. It can be deduced that food integrity refers not only to the safety [18] and quality $[19,20]$ of a food product but also to its authenticity [13] as well as its defense or protection from unintentional contamination hazards and deliberate counterfeiting threats [17,21-23].

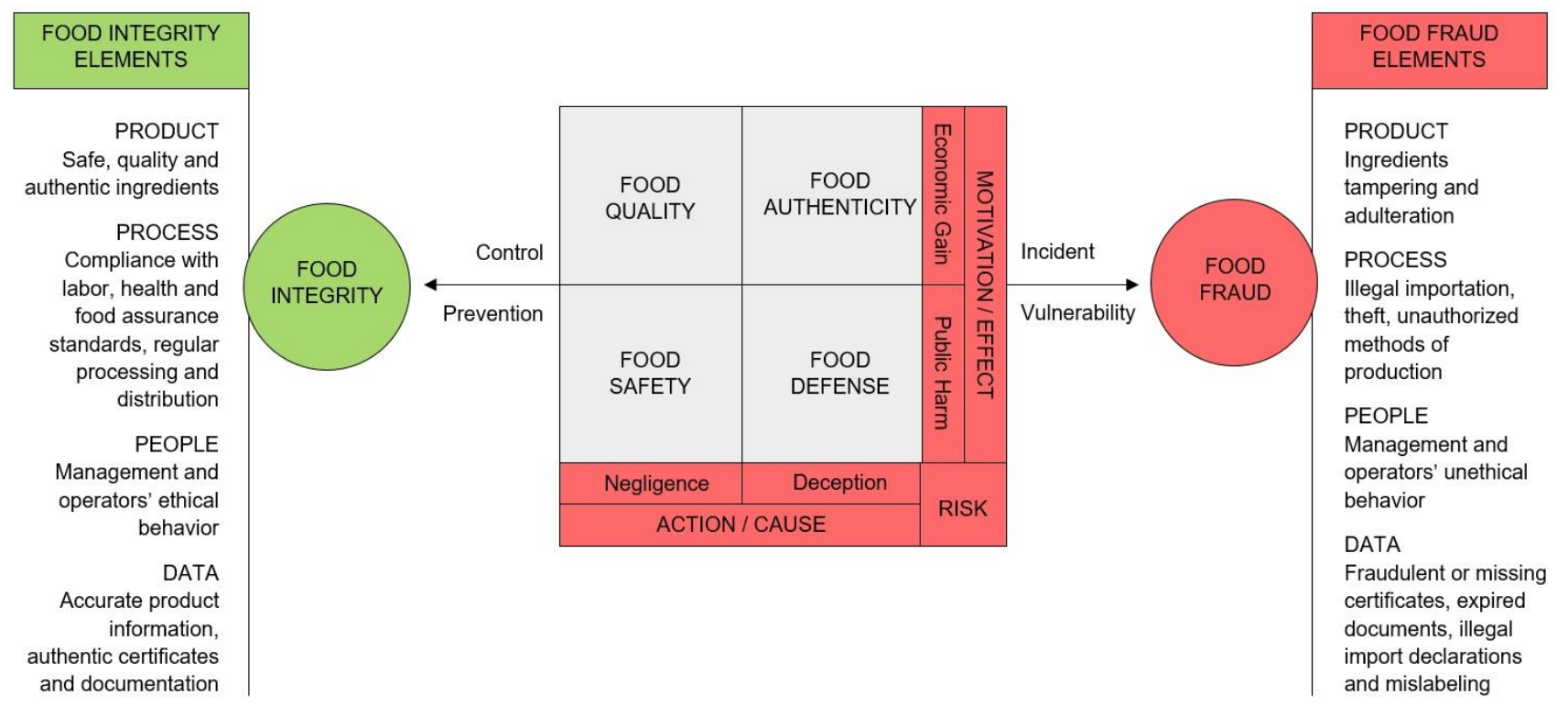

Figure 1. Schematic representation of the nature and interconnection of food integrity and food fraud elements. As two opposed faces of the same coin, food integrity and food fraud both concern the entirety of the food supply chain aspects involved in the food production, including product, process, people, and data, as well as the activities employed in the monitoring of food, such as quality, safety, authenticity, and defense. In the case of food fraud, such elements and activities are managed fraudulently and improperly causing incidents and vulnerability along the food supply chain. Oppositely, food integrity represents the ethical manner and preventive approach through which food companies control the overall food production (adapted from Spink and Moyer (2011) [24] and Manning (2016) [8]).

While food quality and food safety hazards occur mostly unintentionally or as a consequence of negligent handling of food and limited control during the production stages, food authenticity and food defense threats are intentionally perpetrated to deceive consumers through mislabeling and counterfeiting (Figure 1). Food quality and food 
authenticity incidents affect primarily the economic sphere, whereas food safety and food defense risks may severely impact public health [24].

Food integrity comprises in its notion all the properties of a food product included in the common definitions of food safety, quality, authenticity, and defense [6]. These concepts are, in fact, product-centric referring to one or more aspects of food, such as ingredients, production methods, and supportive documentation, whereas the notion of food integrity overarches them all and is system-centric [11]. Therefore, the relation between food integrity and food fraud is inversely proportional, as also demonstrated by Manning (2016) [8], who explains food fraud as the result of a misrepresentation associated with product, process, people, and data integrity, as detailed in Figure 1 (right side). When all aspects related to food quality, safety, authenticity, and defense are kept under control through efficient risk assessment, management, and prevention systems, food integrity may be achieved. Contrarily, companies will be vulnerable to food fraud.

Based on all the arguments above, aiming to achieve a unanimous definition, we define food integrity as "a multidimensional concept concerning the integrity of product, process, people, and data, implying the controlled status of a food product to be intact, safe, of quality, and authentic in its claims, as well as sourced, processed, and distributed ethically throughout a food supply chain."

This definition aligns with the general concept of integrity described by Jacobs (2004) [25], who explains integrity as existing within two categories: physical and moral integrity. In the first conception, integrity applies to the physical state of undivided wholeness, while in the latter, it connotes an unimpaired moral state, characterized by innocence, uprightness, honesty, and sincerity, mostly in the context of business ethics.

\subsection{Conceptualizing Food Integrity Climate}

In a business environment, organizational climate refers to the shared perceptions and the meaning attached to the policies, practices, and procedures employees experience at work and the behaviors they observe that are supported and expected [26]. It originates from individual perceptions derived from workers making sense of their work environment that become shared when they converge in the same organization [27]. Previous studies identified five key types of perceptions, such as leadership, communication, commitment, risk awareness, and resources as fundamental human aspects of a company's climate [28-35].

The relevance of these five human drivers of a company's climate has been demonstrated in the context of food safety [16] where a positive relationship between the food safety climate as perceived by employees and their food-related behavior was found. A similar relationship and the role of these five climate components was replicated in the endovascular surgery field, showing a strong positive direct and indirect effect of the perceived radiation safety climate on radiation safety behaviors of team members [36].

These human or climate components remain unstudied in the domain of food integrity. As it is assumed that the five climate components are also relevant in the context of food integrity, they were integrated with the four food integrity elements (product, process, people, and data integrity) distinguished by Manning (2016) [8], defined in Figure 2, for the elaboration of the food integrity climate definition. 


\begin{tabular}{|c|c|c|}
\hline FOOD INTEGRITY ELEMENTS & & CLIMATE COMPONENTS \\
\hline $\begin{array}{r}\text { PRODUCT INTEGRITY } \\
\text { Intrinsic characteristics or inherent quality attributes of totality and } \\
\text { completeness of a food product, implying the safety, quality, } \\
\text { genuineness and authenticity of its non-adulterated components } \\
\text { with verifiable and recognized origins } \\
\text { PROCESS INTEGRITY } \\
\text { Extrinsic characteristics or activities undertaken to produce the } \\
\text { food item encompassing the design, packaging, monitoring and } \\
\text { verification of processes within the product life-cycle to ensure } \\
\text { that they remain authentic and intact, including compliance with } \\
\text { food assurance standards of hygiene, animal welfare, plant } \\
\text { health, labor, as well as controlled methods of production, } \\
\text { processing and distribution } \\
\text { PEOPLE INTEGRITY } \\
\text { Moral characteristics of honest behavior as well as ethical beliefs } \\
\text { and attitudes exhibited by the people working in the organization }\end{array}$ & $\begin{array}{c}\text { FOOD } \\
\text { INTEGRITY } \\
\text { CLIMATE }\end{array}$ & $\begin{array}{l}\text { LEADERSHIP } \\
\text { Extent to which the organization's leaders are able to engage the } \\
\text { employees in food integrity performance and compliance to meet } \\
\text { the company's goals, vision and standards } \\
\text { COMMUNICATION } \\
\text { Level of quality of transfer of food integrity-related information } \\
\text { and knowledge within all parties of the organization } \\
\text { COMMITMENT } \\
\text { Level of engagement and involvement towards food integrity of } \\
\text { all parties and hierarchical levels in the organization, including } \\
\text { their own values and beliefs in food safety matters } \\
\text { RISK AWARENESS } \\
\text { Extent to which the organization is aware of the risks concerning } \\
\text { food integrity and has measures in act to control them } \\
\text { RESOURCES } \\
\text { Extent to which physical and non-physical means are present in } \\
\text { the company, including its internal organizational structures and } \\
\text { processes, such as personnel, infrastructure, education, training, } \\
\text { time, procedures and policies, to foster integrity within the } \\
\text { organization }\end{array}$ \\
\hline
\end{tabular}

Figure 2. Conceptual model of the food integrity climate. The concept of a food integrity climate is constituted by the combination of food integrity elements (product, process, people, and data integrity) [8] and the components of a company's climate (leadership, communication, commitment, risk awareness, and resources) [16].

We define food integrity climate as "the employees' shared perception of leadership, communication, commitment, risk awareness, and resources regarding food integrity within the company's working environment in terms of product, process, people, and data integrity."

\subsection{Development of the Food Integrity Climate Self-Assessment Tool}

Based on the proposed food integrity climate definition and elements, a self-assessment tool was developed to assess the food integrity performance level as perceived by employees of food companies along the supply chain. As the overall aim was to capture human perceptions, a self-report type of measure was adopted in the form of a questionnaire that employees could fill out. This choice is in line with the widespread use of self-reported scales, where self-assessment surveys have been used to investigate employees' perceptions, knowledge, and behavior regarding a variety of organizational issues, even in the fields of food safety [16,37-39] and food fraud [4].

The FIC tool was structured with four sections, one for each food integrity element. For each section, five indicators were developed, one for each of the five key climate components. The twenty resulting indicators, or questions in the form of statements, were elaborated content-wise by combining the defining attributes of the four food integrity elements with those of the five climate components, adapted to suit food integrity-related matters, as shown in Table 1. 


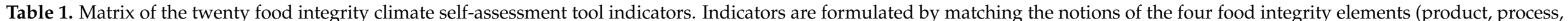

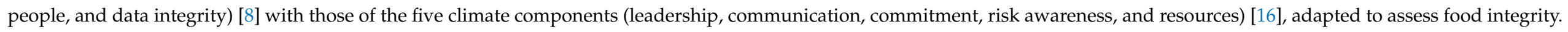

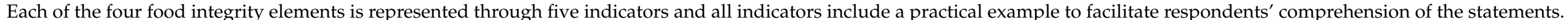

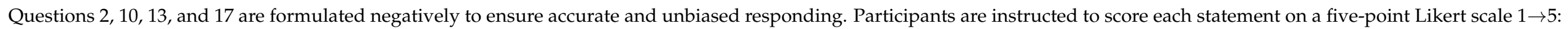

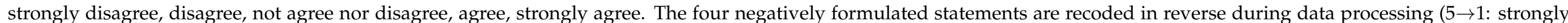

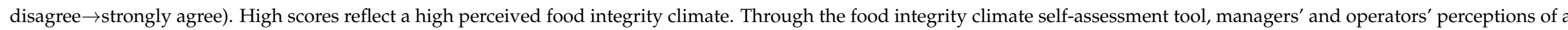
company's food integrity level can be analyzed, acknowledging the human dimension involved in the decision-making processes. (See full questionnaire in Appendix A).

\begin{tabular}{|c|c|c|c|c|c|c|}
\hline & & \multicolumn{5}{|c|}{ CLIMATE } \\
\hline & & Leadership & Communication & Commitment & Risk Awareness & Resources \\
\hline \multirow{3}{*}{ 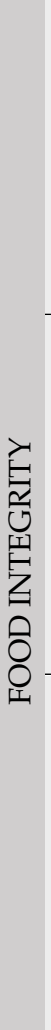 } & 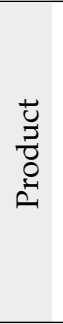 & $\begin{array}{l}\text { Q1. In my company, leaders set } \\
\text { clear objectives and goals on how to } \\
\text { achieve product integrity (e.g., } \\
\text { leaders give precise tasks and } \\
\text { deadlines to employees to deliver } \\
\text { products as required by industry } \\
\text { standards and according to the } \\
\text { company's recipes). }\end{array}$ & $\begin{array}{l}\text { Q2. In my company, there is } \\
\text { unclear communication with } \\
\text { employees on how to achieve } \\
\text { product integrity (e.g., employees' } \\
\text { questions about product } \\
\text { requirements, composition and } \\
\text { recipes are often badly answered). }\end{array}$ & $\begin{array}{l}\text { Q3. In my company, the } \\
\text { importance of product integrity } \\
\text { is recognized (e.g., leaders and } \\
\text { employees' main priority is to } \\
\text { meet high product standards } \\
\text { and fulfill customer } \\
\text { requirements). }\end{array}$ & $\begin{array}{l}\text { Q4. In my company, leaders and } \\
\text { employees are } \\
\text { aware of the hazards and threats } \\
\text { related to product integrity (e.g., } \\
\text { ingredients adulteration or } \\
\text { contamination and product } \\
\text { counterfeit or imitation are avoided). }\end{array}$ & $\begin{array}{l}\text { Q5. In my company, the } \\
\text { necessary resources are } \\
\text { available to achieve product } \\
\text { integrity (e.g., good selection of } \\
\text { suppliers and raw materials, } \\
\text { trained staff and sufficient time } \\
\text { to work and perform controls } \\
\text { are guaranteed). }\end{array}$ \\
\hline & 总 & $\begin{array}{l}\text { Q6. In my company, leaders have } \\
\text { clear expectations on how to } \\
\text { achieve process integrity (e.g., } \\
\text { leaders require and trust employees } \\
\text { to perform processes according to } \\
\text { instructions and standard operating } \\
\text { procedures). }\end{array}$ & $\begin{array}{l}\text { Q7. In my company, there is } \\
\text { clear communication with } \\
\text { employees on how to achieve } \\
\text { process integrity (e.g., employees } \\
\text { understand well leaders' } \\
\text { explanations on how to execute } \\
\text { and supervise all the steps of } \\
\text { product processing). }\end{array}$ & $\begin{array}{l}\text { Q8. In my company, leaders and } \\
\text { employees } \\
\text { act properly and constructively } \\
\text { to solve issues that affect process } \\
\text { integrity (e.g., leaders are } \\
\text { prepared to face emergencies; } \\
\text { employees are ready to correct } \\
\text { incidents or non-compliances on } \\
\text { the production line). }\end{array}$ & $\begin{array}{l}\text { Q9. In my company, leaders and } \\
\text { employees are } \\
\text { aware of the hazards and threats } \\
\text { related to process integrity (e.g., } \\
\text { equipment, production line and } \\
\text { processing methods are kept under } \\
\text { control). }\end{array}$ & $\begin{array}{l}\text { Q10. In my company, the } \\
\text { necessary resources are not } \\
\text { always available to achieve } \\
\text { process integrity (e.g., } \\
\text { equipment, replacement parts, } \\
\text { workspaces and systems for } \\
\text { production and process } \\
\text { monitoring are not sufficient or } \\
\text { satisfactory). }\end{array}$ \\
\hline & $\begin{array}{l}\stackrel{0}{a} \\
\text { वे } \\
\text { व }\end{array}$ & $\begin{array}{l}\text { Q11. In my company, leaders } \\
\text { aim to continuously improve } \\
\text { people integrity (e.g., leaders } \\
\text { motivate, involve and listen to } \\
\text { employees' concerns and } \\
\text { suggestions, behave ethically and } \\
\text { lead as role models). }\end{array}$ & $\begin{array}{l}\text { Q12. In my company, the } \\
\text { importance of people integrity } \\
\text { and ethical behavior is } \\
\text { communicated (e.g., employees } \\
\text { are encouraged to discuss openly } \\
\text { and honestly with leaders and } \\
\text { colleagues). }\end{array}$ & $\begin{array}{l}\text { Q13. In my company, working } \\
\text { to improve people integrity by } \\
\text { behaving ethically is not } \\
\text { recognized or rewarded (e.g., } \\
\text { incentives or positive feedback } \\
\text { are not given to employees; } \\
\text { dishonest behavior is often } \\
\text { ignored or tolerated). }\end{array}$ & $\begin{array}{l}\text { Q14. In my company, people integrity } \\
\text { is fostered by being } \\
\text { careful, alert and attentive to } \\
\text { potential hazards and threats (e.g., } \\
\text { employees care about each other's } \\
\text { well-being; leaders respect employees' } \\
\text { rights and take customers' health } \\
\text { seriously). }\end{array}$ & $\begin{array}{l}\text { Q15. In my company, } \\
\text { sufficient investments are made } \\
\text { to improve people integrity (e.g., } \\
\text { good working conditions, } \\
\text { ethical code of conduct, conflict } \\
\text { mediation service, employees' } \\
\text { training are offered; differences } \\
\text { between people and diversity } \\
\text { are respected). }\end{array}$ \\
\hline
\end{tabular}


Table 1. Cont.

\begin{tabular}{|c|c|c|c|c|c|}
\hline & \multicolumn{5}{|c|}{ CLIMATE } \\
\hline & Leadership & Communication & Commitment & Risk Awareness & Resources \\
\hline صี & $\begin{array}{l}\text { Q16. In my company, leaders } \\
\text { aim to continuously improve the } \\
\text { level of data integrity (e.g., leaders } \\
\text { always verify the quality of the data } \\
\text { they receive from suppliers and } \\
\text { make sure that food products are } \\
\text { delivered as promised in the label } \\
\text { and advertisements). }\end{array}$ & $\begin{array}{l}\text { Q17. My company communicates } \\
\text { badly on the importance of data } \\
\text { integrity (e.g., employees receive } \\
\text { insufficient written guidelines or } \\
\text { receive unclear oral directions on } \\
\text { how to prepare, verify and record } \\
\text { precise product information). }\end{array}$ & $\begin{array}{l}\text { Q18. In my company, leaders } \\
\text { are committed to data integrity } \\
\text { by setting a good example (e.g., } \\
\text { leaders supervise and } \\
\text { participate in work activities } \\
\text { ensuring that labels match } \\
\text { product properties and product } \\
\text { information is recorded and } \\
\text { provided correctly). }\end{array}$ & $\begin{array}{l}\text { Q19. In my company, leaders and } \\
\text { employees have a } \\
\text { realistic picture of hazards and threats } \\
\text { related to data integrity (e.g., false } \\
\text { documents, invalid statistics or } \\
\text { figures, irregular certificates and } \\
\text { incorrect labeling are avoided). }\end{array}$ & $\begin{array}{l}\text { Q20. In my company, } \\
\text { sufficient investments are made } \\
\text { to achieve data integrity (e.g., } \\
\text { specific instructions and } \\
\text { procedures, good tracking and } \\
\text { tracing software, product } \\
\text { registration databases and data } \\
\text { recording programs are } \\
\text { available). }\end{array}$ \\
\hline
\end{tabular}


To facilitate the comprehension of the questionnaire indicators, concrete situational examples were added to each statement. Definitions of food integrity and its elements were given at the beginning of each section in a user-friendly language. To avoid response biases by participants, such as acquiescence and social desirability, which can be a drawback with self-report measures, and to assure content validity, sixteen positively formulated items were mixed with four negative or reversed items (one for each section: Q2, Q10, Q13, and Q17) [40-43].

Since the goal of the tool was to investigate the food integrity climate from employees point of view, a five-point Likert response scale was adopted [16,44-48]. Respondents were asked to evaluate each indicator from 1 to 5 , corresponding to strongly disagree (1), disagree (2), not agree nor disagree (3), agree (4), and strongly agree (5), where responses closer to 5 imply a better-perceived food integrity climate depending on the particular indicator. The answer scale of the four negatively formulated indicators was afterward recoded in reverse order during the data processing. The final version of the FIC tool is reported in Appendix A.

\subsubsection{Indicator Rationale for the Food Integrity Climate Element: Product}

Setting clear objectives in an organization enables the measurement of performance against the defined targets, which represents a first critical step for the continuous improvement towards food safety and, by extension, food integrity [29]. Good management within an organization involves planning, organizing, leading, and controlling goal-oriented activities. Leaders should coordinate and oversee the work of the employees so that the activities are completed efficiently and effectively [49]. As such, statement Q1 was introduced in the questionnaire (see Table 1).

Regular and clear social exchanges between leaders and employees can lead to better communication concerning food integrity matters. Leaders should communicate often and plainly with their employees to ensure that employees are aware of their roles and responsibilities [29]. Thus, Q2 was introduced.

Leaders must demonstrate that achieving food integrity is more important than productivity and profit. If employees' own beliefs and values align with those of the organization, they will be more motivated to achieve food integrity and exceed expectations, as they will not see it merely as their task, but believe in it [31,32]. Leaders with integrity sell more effectively because they seek to sell genuinely valuable products [50]. Therefore, Q3 was introduced.

Risk perception and the subsequent risk-taking behavior are critical for achieving a good food safety climate and, in general, a good food integrity climate. Risks should be known by the employees, so they can take them into account in their daily work decisions and avoid incidents [31]. To prevent food supply chain fraud, leaders must understand the factors that enable the occurrence of risks, such as criminal actions able to deceive existing scientific testing processes [1]. Hence, Q4 was introduced.

If employees are given sufficient time to work in a way that will ensure the achievement of food integrity, they will likely perceive a high psychological and emotional support from their organization. High perceived organizational support also implies that sufficient staff are available to follow up and collaborate on daily working activities, so that every staff member may have sufficient time to work efficiently to achieve food integrity [31]. Furthermore, measures such as contractual requirements with suppliers addressing specifically fraud prevention, extensive self-regulation and social control across the supply chain, transparent feedback, and actions on criminal behavior to enhance fraud awareness and support fraud mitigation measures can contribute to the reduction of fraud vulnerability [4]. Accordingly, Q5 was introduced. 


\subsubsection{Indicator Rationale for the Food Integrity Climate Element: Process}

Efficient leaders set clear expectations for the employees so that all the employees in the organization know what is expected from each one of them and what they are required to do to meet such expectations [29]. As such, Q6 was introduced in the questionnaire.

Appropriate communication and language should be used and additional effort should be spent to ensure that food integrity-related messages are clear to employees who do not always share the same language as the leaders [33]. Thus, Q7 was introduced.

Leaders should be committed to ensuring food integrity, and consider this a priority by responding quickly and actively to solve potential problems. Remarks concerning food integrity issues should be addressed constructively and respectfully to avoid a blame culture, in which employees are discouraged to admit their mistakes because of possible negative consequences $[30,31]$. Employees with high integrity are more rational, honest, independent, as well as innovative and productive [51]. Furthermore, leader behavioral integrity can improve error reporting and error management within the organization, leading to a reduction in malpractices and food fraud risks [52]. Contingency plans should also be present to deal with potential emergencies and to ensure that incidents do not escalate [4]. Accordingly, Q8 was introduced.

It is important for leaders and employees to feel they can trust and rely on the performance of the organization's food safety management systems and food fraud prevention strategies. Such trust can motivate employees to remain committed toward the achievement and improvement of food integrity [35]. Trust is needed within the organization and along the whole food supply chain, and such trust can only be created and maintained if promises are kept and guaranteed by effective and efficient controls [14]. Therefore, Q9 was introduced.

Organizational support is reflected by the availability of the necessary infrastructure, such as proper equipment and workspaces, and sufficient technical and financial resources to assist in the achievement of food integrity [29]. Monitoring systems to supervise processes and control fraud are essential tools for organizations and should be in place to evaluate, remedy, and improve food fraud prevention and detection techniques [4]. Hence, Q10 was introduced.

\subsubsection{Indicator Rationale for the Food Integrity Climate Element: People}

As employees are the frontline workers on the organization's work floor, they are often the first to notice deviations and expose issues and opportunities on food integrity matters. Therefore, it is important and beneficial for leaders to listen to employees' comments and suggestions [29]. If employees recognize that they have a critical role in the achievement of food integrity, they will also feel proud about the positive results of the organization [30,31]. From the perspective of integrity, the task of leadership is to define and give life to an organization's guiding values, to create an environment that supports ethical behavior, and to instill a sense of shared accountability among employees [53]. As such, Q11 was introduced in the questionnaire.

Employees should feel free to approach colleagues who are engaged in behavior that can be potentially harmful and to openly discuss with leaders about food integrity issues within their organization. This will contribute to the openness and honesty within the organization and may be beneficial for the food integrity climate [28,31]. When leaders are not open and honest at all times, employees will feel that they can get away with lying occasionally, including deceiving supervisors or falsifying reports and records. Thus, Q12 was introduced.

Consequences determine whether a behavior is repeated. Positive consequences stimulate good behavior, while negative ones are less effective in influencing long-term behavioral change, working rather on the short term [29]. Leaders should motivate their employees, give positive feedback and acknowledge good behavior [31]. A culture characterized by demotivation, mistrust, and dissatisfaction can be a breeding ground for unethical behaviors among employees. Unethical business cultures lead to the normaliza- 
tion of committing food fraud, which reinforces longer-term fraudulent activity within the organization and supply chain [4]. Therefore, Q13 was introduced.

Employees' trust and positive commitment to the organization's systems and strategies can be enhanced if employees perceive that their colleagues and leaders are alert, attentive, and carefully considering food integrity issues in the right manner. If employees think that leaders overestimate or underestimate risks, they will be less inclined to strive to achieve high levels of food integrity [31]. Leaders with moral integrity do not justify low wages and poor working conditions by their firms' need to be competitive and profitable [25]. Hence, Q14 was introduced.

Many integrity initiatives have structural features common to compliance-based initiatives: a code of conduct, training in relevant areas of law, mechanisms for reporting and investigating potential misconduct, and audits and controls to ensure that laws and company standards are met [53]. Frequent education and training concerning food integrity are needed to achieve behavioral change [29]. Ethical codes of conduct consist of moral standards which help to guide employee or corporate behavior. Codes of conduct are favorable toward the creation of a stronger ethical corporate climate and relate to positive ethical behavior, reducing food fraud vulnerability [4]. Accordingly, Q15 was introduced.

\subsubsection{Indicator Rationale for the Food Integrity Climate Element: Data}

Leaders striving for continuous improvement often denote strong leader ambition and reflect the importance of working to achieve food integrity within the organization and outside [16]. With regard to data integrity, the striving for continuous improvement within a food organization implies being honest and correct about product information. As such, Q16 was introduced in the questionnaire.

If employees are constantly reminded of the importance of food integrity through clear communication, they will be more inclined to adopt this belief. The use of various mediums to convey food integrity-related messages can increase effectiveness [29]. Accordingly, Q17 was introduced.

Leaders should set a good example concerning food integrity since the actions of the leaders will be adopted by the employees. If leaders participate in the critical everyday tasks, demonstrating the importance of food integrity, employees will pay more attention to safety and integrity matters themselves [31]. Leaders should serve as role models by following proper food integrity practices themselves. Leader behavioral integrity is, in fact, critical for shaping employee attitudes [52]. Creating an organization that encourages exemplary conduct may be the best way to prevent damaging misconduct [53]. Hence, Q18 was introduced.

Effective risk communication is essential to ensure that both leaders and employees possess a realistic picture of the potential risks concerning food integrity in the organization and act accordingly [31]. Leaders' risk communication is an effective technique to achieve behavioral change since it can positively influence employees' risk awareness and how employees will act in matters related to food integrity [34]. Unless food supply chains take the holistic view of food fraud and mitigation strategies to the core of their operations, the criminal elements will always have a gap in the chain that can be exploited [54]. Therefore, Q19 was introduced.

Effective procedures and instructions concerning food integrity-related matters should be constantly reminded, written down, and documented within the organization to ensure that employees clearly know what is expected from them to prevent deviations and doubts about specific processes and activities [29]. Furthermore, the use of indirect data, such as those from tracking and tracing systems can contribute to fraud control. Due to the ability to find information on the history, process, as well as the location of a product or ingredient, traceability tools can be used to prevent or eliminate illegal, unreported, and unregulated products [4]. Thus, Q20 was introduced. 


\subsection{Expert Validation of the Food Integrity Climate Self-Assessment Tool}

Results of the relevance evaluation and the importance rating are reported in Table 2. All indicators were considered relevant by more than $50 \%$ of the experts. Therefore, none of the twenty indicators were considered for deletion. Based on the median calculation of the importance ratings, the tool could be considered valid, as all the indicators were rated overall from very important (1) to important (2).

Table 2. Expert validation results based on the relevance and importance rating of the food integrity climate self-assessment tool indicators.

\begin{tabular}{ccc}
\hline Indicator & ${\text { Relevance }{ }^{\mathbf{a}, \mathbf{b}}}$ & Importance $^{\mathbf{c}, \mathbf{d}, \mathbf{e}}$ \\
\hline Q1 & Product Integrity & \\
Q2 & $12(12)$ & $2(1.83)(0.69)$ \\
Q3 & $8(12)$ & $2(2.25)(0.92)$ \\
Q4 & $12(12)$ & $1(1.33)(0.47)$ \\
Q5 & $12(12)$ & $1(1.33)(0.47)$ \\
& $11(11)$ & $1(1.18)(0.39)$ \\
Q6 & Process Integrity & \\
Q7 & $10(11)$ & $1(1.82)(1.03)$ \\
Q8 & $12(12)$ & $1(1.50)(0.65)$ \\
Q9 & $12(12)$ & $2(1.75)(0.72)$ \\
Q10 & $12(12)$ & $2(2.08)(0.86)$ \\
& $8(11)$ & $2(2.09)(1.00)$ \\
Q11 & People Integrity & $2(1.83)(0.69)$ \\
Q12 & $12(12)$ & $2(2.17)(0.99)$ \\
Q13 & $11(12)$ & $2(1.91)(0.90)$ \\
Q14 & $10(11)$ & $2(1.73)(0.75)$ \\
Q15 & $11(11)$ & $2(1.91)(0.79)$ \\
& $10(11)$ & \\
Q16 & Data Integrity & $1(1.33)(0.62)$ \\
Q17 & $12(12)$ & $2(1.82)(0.94)$ \\
Q18 & $8(11)$ & $2(2.08)(0.95)$ \\
Q19 & $10(12)$ & $2(2.00)(0.71)$ \\
Q20 & $11(12)$ & $1(1.33)(0.47)$ \\
\hline
\end{tabular}

${ }^{a}$ Number of experts considering the indicator relevant. ${ }^{b}$ Total number of respondents for the indicator. ${ }^{c}$ Median of the importance rating $\left(1 \rightarrow 4\right.$ : very important $\rightarrow$ not important). ${ }^{d}$ Mean of the importance rating $(1 \rightarrow 4$ : very important $\rightarrow$ not important). ${ }^{\text {e }}$ Standard deviation of the importance rating $(1 \rightarrow 4$ : very important $\rightarrow$ not important).

No new indicator was added to the questionnaire based on the information provided by the experts in the open suggestions. However, some minor lexical modifications and textual adjustments were made to improve the clarity of a few statements. The final version of the indicators and the tool are reported respectively in Table 1 and Appendix A.

\subsection{Testing in Practice of the Food Integrity Climate Self-Assessment Tool}

Statistical exploration of the data showed remarkable findings. Firstly, the company's overall food integrity climate as perceived by all the participating employees (managers and operators) $(n=52)$ was high (mean $=86.73 / 100)$. The total sample perceived the product integrity to be the best-performing food integrity element $($ mean $=22.10 / 25)$, while the people integrity was the lowest-performing one (mean $=21.19 / 25)$. With regard to the climate components, the best performing component was perceived to be the leadership $($ mean $=17.71 / 20)$, while the worst performing was the one related to the company's resources (mean $=16.92 / 20)$.

Secondly, statistical differences among the eight affiliates were found regarding the perceived food integrity climate. Affiliates could be clustered in three different groups: (1) three affiliates evaluated the food integrity climate as very high (means range $=90$ $100 / 100$ ), (2) four different affiliates rated it as high (means range $=80-90 / 100$ ), and (3) the remaining affiliate scored it as medium (mean range $=70-80 / 100$; mean $=70.67 / 100$ ). 
Even though the results are not representative of the full organization (only eight affiliates from the over three hundred butcher shops were involved), it could be noted that the two best scoring affiliates perceived the data integrity as the best-performing food integrity element (mean $=24.67 / 25)$, while the worst scoring affiliate evaluated people integrity as the lowest-performing food integrity element $($ mean $=16.00 / 25)$.

Thirdly, no significant statistical differences were found in the mean scores for the overall food integrity climate nor in the mean scores for the four food integrity elements separately regarding the perceptions between operators and their managers in comparison. Both subsamples perceive a similar high food integrity climate (management mean $=87.22 / 100$; operators mean $=86.47 / 100$ ).

Concerning the four food integrity elements, the management rated product and people integrity slightly higher than the operators, while the operators perceived process and data integrity slightly higher than the management, but not significantly different. This may be due to their different organizational roles and tasks. For similar potential reasons, the management estimated the product integrity as the best-performing food integrity element and the process integrity as the worst-performing one. On the other side, operators scored the process integrity as the best-performing food integrity element and the people integrity as the worst-performing one. Mean scores and $p$-values are reported in Table A1 in Appendix B.

Of the five climate components, the company's resources was the component perceived most dissimilarly by the two sample groups, with the management rating this component higher than operators (management mean $=17.89 / 20$; operators mean $=16.41 / 20$ ). This can be explained by the fact that, in the field, tangible and usable things such as the company's resources (e.g., production materials, databases, workspaces, codes of conduct, employees' training, and services) are acknowledged differently by those who remotely administrate them (managers) and those who concretely utilize them in the everyday working practices (operators). No meaningful statistical differences between operators and their managers were found for the other climate components, which are immaterial and abstract dimensions.

A more detailed analysis at each single indicator level revealed statistical differences between management and operators in five indicators (Q2, Q7, Q8, Q15, and Q20), as shown in Table A1 in Appendix B and represented in Figure 3. Managers scored higher than operators in Q2, Q15, and Q20, where two of these indicators (Q15 and Q20) are related to the climate component resources regarding respectively people and data integrity, while Q2 concerns the component communication in relation to product integrity. Operators perceived the climate components communication (Q7) and commitment (Q8) regarding the process integrity better than managers.

These results suggest that human perceptions regarding food integrity might partly be shared within a company across hierarchical levels. The influence of the food integrity climate on organizational functioning depends on the food integrity climate strength, which can be considered as a reflection of the extent of "sharedness" of food integrity climate perceptions among employees [55].

Finally, based on the statistical results obtained from the Cronbach's alpha analysis, it could be deduced that the overall reliability and internal consistency of the FIC tool is high, with an alpha value of 0.89 , which is above the common minimum requirement of 0.7 [56]. Internal consistency of the four subscales, corresponding to the four food integrity elements separately, revealed lower but still acceptable alpha values especially for the product and process integrity scales. In both cases, diminished internal consistency could be attributed to the single negatively formulated item used in both scales (respectively, Q2 and Q10). These two items were not deleted nor reformulated, given the small sample size examined as well as in consideration of the expert validation results and the nomological network of both constructs at hand. With integrity being a sensitive topic potentially leading to socially desirable responding, the use of both positive and negative worded statements may help mitigate the acquiescence bias in responding to a self-reported questionnaire [41,57]. 
Although their use is recommended by psychometrical scholars [40-43], such reversed items might have confused or may not have been noticed by some participants in this study, compared to the neutral or positive worded statements [58,59]. Prior testing of the understanding of the tool and its indicators in the target sample as well as supervised data collection with the researchers are recommended for future applications to prevent potential drawbacks of these negatively formulated statements.
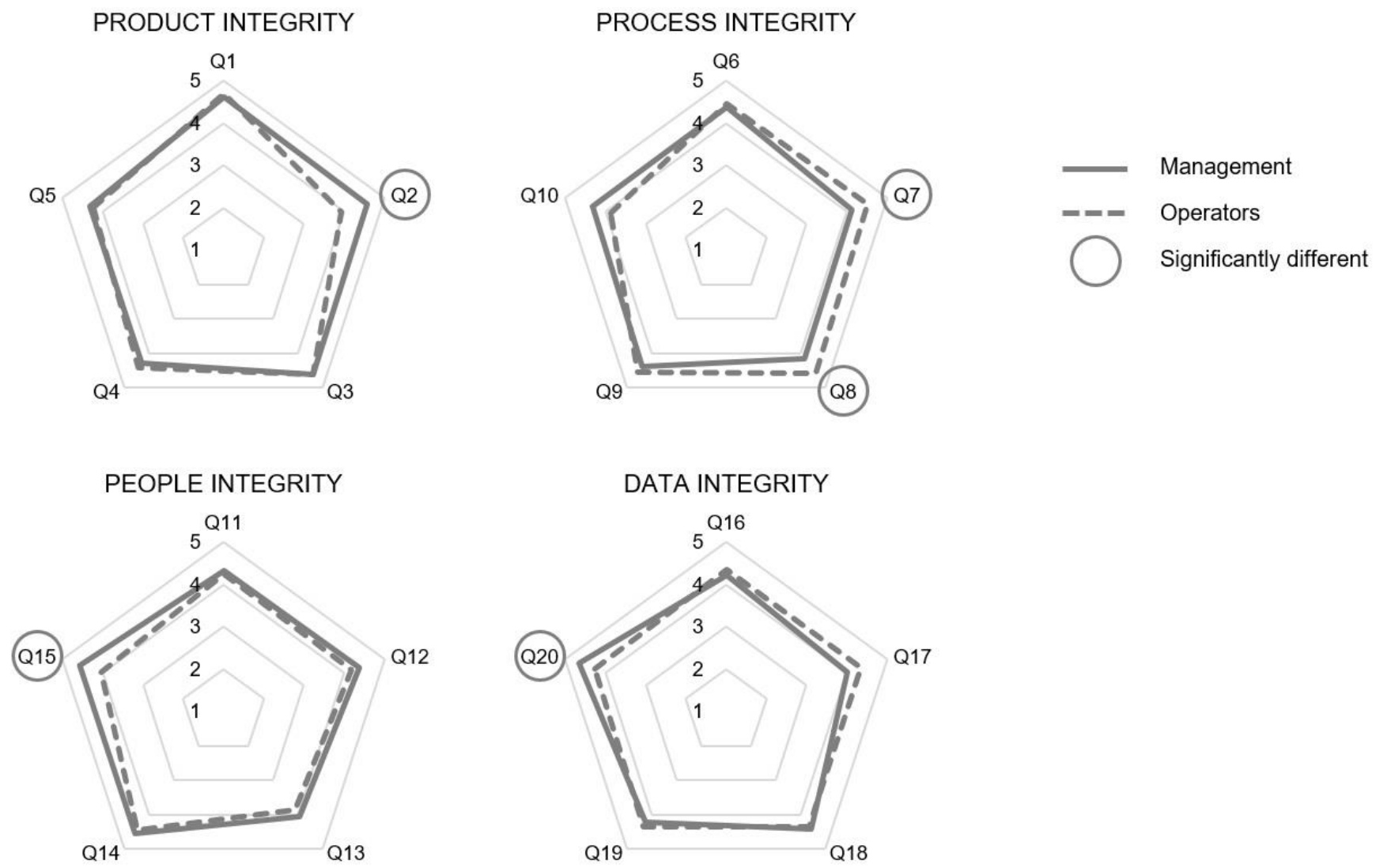

Figure 3. Radar chart with mean results of management $(n=18)$ and operators $(n=34)$ of the participating large-scale meat distribution company on the indicators of the food integrity elements. A five-point Likert answer scale $(1 \rightarrow 5$ : strongly disagree $\rightarrow$ strongly agree) was used. The indicators that showed a statistically significant difference between management and operators' scores are circled $(p<0.05)$. (See mean scores and $p$-values in Table A1 in Appendix B).

\subsection{Limitations and Future Research}

The results from this testing and feedback obtained from the participating company suggest that the FIC tool is clear, understandable, and meaningful. Nonetheless, the outcomes of this study should be considered with caution and further verified in practice in larger groups of respondents and in more heterogeneous samples of food organizations.

Future studies may also examine the relationship between an organization's food integrity climate and its employees' behavioral integrity or (un)ethical behavior on a large scale.

Finally, it must be remembering that the food integrity climate self-assessment tool estimates primarily subjective perceptions on the food integrity performance level of a food company. To consolidate the statements made in this paper, such limitations will be tackled in future research through method triangulation, in which the food integrity climate questionnaire outputs will be integrated and compared to the results obtained from a key performance indicators audit to verify objectively a company's compliance to food integrity standards, and from a food fraud vulnerability assessment tool to get a comprehensive evaluation of the relationship between food fraud and food integrity in a food company. 


\section{Conclusions}

Overall, although based on a single small-scale testing, the results illustrated that operators and managers converged in their food integrity perceptions. Their perceptions slightly differed regarding the amount and type of resources spent by their company to embrace food integrity. Operators rated the process integrity highest, while managers considered the process integrity as the lowest.

The FIC tool helps food companies throughout the supply chain in stepping beyond the existing technological and managerial food fraud prevention strategies, since it allows for a deeper insight into the human dimension behind a company's food integrity through the assessment of five climate components in relation to four food integrity elements. The data collected from the tool assist food businesses in identifying and managing strengths and weaknesses regarding their food integrity climate, and improving performances by evolving from a traditional food safety management system towards a more comprehensive and updated food integrity management system in which food integrity is embraced as a systemic-centric approach inclusive of all technical and non-technical aspects throughout the food supply chain.

Author Contributions: All authors collaborated to design the study and elaborate on the first version of the tool. W.S.A. drafted the first version of the manuscript, collected and processed the data relative to the expert validation and testing of the proposed tool, and interpreted the results. L.J., P.V., and P.A.L. assisted with the data processing, revised extensively the manuscript, and contributed to its final drafting. All authors have read and agreed to the published version of the manuscript.

Funding: This research has been conducted in the context and under the supervision of Ghent University, Belgium, funded by King Abdulaziz City for Science and Technology (KACST) through the Saudi Arabian Cultural Mission (SACM), the Hague, the Netherlands.

Institutional Review Board Statement: The study was conducted in accordance with the ethical standards of first authors' institutional research committee and with the 1964 Helsinki declaration and its later amendments.

Informed Consent Statement: Informed consent was obtained from all subjects involved in the study.

Acknowledgments: We acknowledge and thank the meat distribution company that performed the study.

Conflicts of Interest: The authors declare no conflict of interest. The sponsors had no role in the design, execution, interpretation, or writing of the study.

\section{Appendix A}

\section{Food Integrity Climate Questionnaire}

Thanks for agreeing to participate in our research. This questionnaire investigates the food integrity climate in your company. Responses are completely anonymous and will be treated confidentially.

Food integrity refers to the status of a food product to be intact, safe, of quality, nutritional, authentic in its claims, as well as sourced, produced, and distributed ethically.

Please read the 20 following statements and indicate each time whether you strongly disagree, disagree, not agree nor disagree, agree, or strongly agree by circling the number that represents your answer. 


\section{PRODUCT INTEGRITY}

Product integrity means that a food product is safe for human consumption, of quality, genuine, with pure and non-adulterated ingredients from recognized and true origins (e.g., product components are not substituted or diluted with cheaper ingredients of lower value or from non-declared origins).

Q1 In my company, leaders set clear objectives and goals on how to achieve product integrity (e.g., leaders give precise tasks

and deadlines to employees to deliver products as required by industry standards and according to the company's recipes).

Strongly

disagree

\section{Disagree Not agree}

nor disagree
Strongly

agree

Q2

In my company, there is unclear communication with employees on how to achieve product integrity (e.g., employees' questions about product requirements, composition, and recipes are often badly answered).

Q3 In my company, the importance of product integrity is recognized (e.g., leaders and employees' main priority is to meet high product standards and fulfill customer requirements).

Q4 In my company, leaders and employees are aware of the hazards and threats related to product integrity (e.g., ingredients adulteration or contamination and product counterfeit or imitation are avoided).

Q5 In my company, the necessary resources are available to achieve product integrity (e.g., good selection of suppliers and raw materials, trained staff, and sufficient time to work and perform controls are guaranteed).

\section{PROCESS INTEGRITY}

Process integrity means that a food product is produced using controlled and regular methods of production, where processes are well executed and assurance standards for food, packaging, hygiene, labor, animal and plant health are followed.

$\begin{array}{lllll}1 & 2 & 3 & 4 & 5\end{array}$

$\begin{array}{lllll}1 & 2 & 3 & 4 & 5\end{array}$

5

1

1

2

3

5

\begin{tabular}{ccccc}
1 & 2 & 3 & 4 & 5 \\
1 & 2 & 3 & 4 & 5 \\
$\begin{array}{c}\text { Strongly } \\
\text { disagree }\end{array}$ & Disagree & $\begin{array}{c}\text { Not agree } \\
\text { nor disagree }\end{array}$ & Agree & $\begin{array}{c}\text { Strongly } \\
\text { agree }\end{array}$ \\
\hline 1
\end{tabular}

Q6 In my company, leaders have clear expectations on how to achieve process integrity (e.g., leaders require and trust employees to perform processes according to instructions and standard operating procedures).

Q7 In my company, there is clear communication with employees on how to achieve process integrity (e.g., employees understand well leaders' explanations on how to execute and supervise all the steps of product processing).

In my company, leaders and employees act properly and constructively to solve issues that affect process integrity (e.g.,

Q8 leaders are prepared to face emergencies; employees are ready to correct incidents or non-compliances on the production line).

In my company, leaders and employees are aware of the hazards and threats related to process integrity (e.g., equipment, production line, and processing methods are kept under control).

(1)

1

2

5

(n my company, hecessary

$\begin{array}{lllll}1 & 2 & 3 & 4 & 5 \\ 1 & 2 & 3 & 4 & 5 \\ 1 & 2 & 3 & 4 & 5\end{array}$




\section{PEOPLE INTEGRITY}

People integrity means that the people working in a company behave honestly and have ethical beliefs and attitudes (e.g., leaders and employees carefully respect rules and comply with high standards).

Strongly
disagree Disagree $\begin{gathered}\text { Not agree } \\ \text { nor disagree }\end{gathered}$ Agree $\begin{gathered}\text { Strongly } \\ \text { agree }\end{gathered}$

Q11 In my company, leaders aim to continuously improve people's integrity (e.g., leaders motivate, involve and listen to employees' concerns and suggestions, behave ethically, and lead as role models).

Q12 In my company, the importance of people integrity and ethical behavior is communicated (e.g., employees are encouraged to discuss openly and honestly with leaders and colleagues).

In my company, working to improve people's integrity by behaving ethically is not recognized or rewarded (e.g., incentives or positive feedback are not given to employees; dishonest behavior is often ignored or tolerated).

1

1

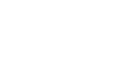

3

1

3

Q13

Q14

In my company, people's integrity is fostered by being careful, alert, and attentive to potential hazards and threats (e.g., employees care about each other's well-being; leaders respect employees' rights and take customers' health seriously).

In my company, sufficient investments are made to improve people's integrity (e.g., good working conditions, ethical code of conduct, conflict mediation service, employees' training are offered; differences between people and diversity are respected).

\section{DATA INTEGRITY}

Data integrity means that all the information regarding a food product is true and accurate, including regular health certifications, valid import documents, and correct product labeling, such as ingredient list, nutritional and technical specifications, origins, and expiry dates.

In my company, leaders aim to continuously improve the level of data integrity (e.g., leaders always verify the quality of the data they receive from suppliers and make sure that food products are delivered as promised in the label and advertisements).

Q17 My company communicates badly on the importance of data integrity (e.g., employees receive insufficient written guidelines or receive unclear oral directions on how to prepare, verify and record precise product information).

In my company, leaders are committed to data integrity by setting a good example (e.g., leaders supervise and participate

Q18 in work activities ensuring that labels match product properties and product information is recorded and provided correctly).

In my company, leaders and employees have a realistic picture of hazards and threats related to data integrity (e.g., false documents, invalid statistics or figures, irregular certificates, and incorrect labeling are avoided).

In my company, sufficient investments are made to achieve data integrity (e.g., specific instructions and procedures, good tracking and tracing software, product registration databases, and data recording programs are available).

2

$\begin{array}{llllll}1 & 2 & 3 & 4 & 5\end{array}$

5

$\begin{array}{lllll}1 & 2 & 3 & 4 & 5\end{array}$

$\begin{array}{llll}2 & 3 & 4 & 5\end{array}$

5


This is the end of the questionnaire. Again, a sincere thank you for your time and collaboration!

\section{Appendix B}

Table A1. Overview of mean scores (overall, dimension-specific, and indicator-specific) and student t-test results of the food integrity climate as perceived by managers $(n=18)$ and operators $(n=34)$ of the large-scale meat distribution company participating in the testing of the FIC tool.

\begin{tabular}{|c|c|c|c|}
\hline & Management & Operators & Student $t$-Test \\
\hline & Mean & Mean & Significance $\left(^{*}\right)$ \\
\hline Food integrity climate & $87.22 / 100$ & $86.47 / 100$ & 0.761 \\
\hline Product integrity & $22.39 / 25$ & $21.94 / 25$ & 0.488 \\
\hline Q1 & $4.61 / 5$ & $4.71 / 5$ & 0.498 \\
\hline Q2 & $4.56 / 5$ & $3.94 / 5$ & $0.015^{*}$ \\
\hline Q3 & $4.61 / 5$ & $4.62 / 5$ & 0.967 \\
\hline Q4 & $4.28 / 5$ & $4.44 / 5$ & 0.500 \\
\hline Q5 & $4.33 / 5$ & $4.24 / 5$ & 0.615 \\
\hline Process integrity & $21.39 / 25$ & $22.03 / 25$ & 0.378 \\
\hline Q6 & $4.39 / 5$ & $4.47 / 5$ & 0.608 \\
\hline Q7 & $4.11 / 5$ & $4.53 / 5$ & $0.045^{*}$ \\
\hline Q8 & $4.17 / 5$ & $4.59 / 5$ & 0.010 * \\
\hline Q9 & $4.39 / 5$ & $4.56 / 5$ & 0.317 \\
\hline Q10 & $4.33 / 5$ & $3.88 / 5$ & 0.202 \\
\hline People integrity & $21.89 / 25$ & $20.82 / 25$ & 0.153 \\
\hline Q11 & $4.33 / 5$ & $4.26 / 5$ & 0.715 \\
\hline Q12 & $4.39 / 5$ & $4.18 / 5$ & 0.212 \\
\hline Q13 & $4.06 / 5$ & $3.88 / 5$ & 0.572 \\
\hline Q14 & $4.56 / 5$ & $4.47 / 5$ & 0.596 \\
\hline Q15 & $4.56 / 5$ & $4.03 / 5$ & $0.008 *$ \\
\hline Data integrity & $21.56 / 25$ & $21.68 / 25$ & 0.866 \\
\hline Q16 & $4.22 / 5$ & $4.35 / 5$ & 0.528 \\
\hline Q17 & $4.00 / 5$ & $4.35 / 5$ & 0.147 \\
\hline Q18 & $4.44 / 5$ & $4.35 / 5$ & 0.624 \\
\hline Q19 & $4.22 / 5$ & $4.35 / 5$ & 0.415 \\
\hline Q20 & $4.67 / 5$ & $4.26 / 5$ & $0.028 *$ \\
\hline
\end{tabular}

\section{References}

1. Manning, L.; Soon, J.M. Developing systems to control food adulteration. Food Policy 2014, 49, 23-32. [CrossRef]

2. Spink, J.; Moyer, D.C.; Speier-Pero, C. Introducing the Food Fraud Initial Screening model (FFIS). Food Control 2016, 69, 306-314. [CrossRef]

3. Silvis, I.; van Ruth, S.; van der Fels-Klerx, H.; Luning, P. Assessment of food fraud vulnerability in the spices chain: An explorative study. Food Control 2017, 81, 80-87. [CrossRef]

4. van Ruth, S.M.; Huisman, W.; Luning, P.A. Food fraud vulnerability and its key factors. Trends Food Sci. Technol. 2017, 67, 70-75. [CrossRef]

5. Ali, M.H.; Suleiman, N. Eleven shades of food integrity: A halal supply chain perspective. Trends Food Sci. Technol. 2018, 71, 216-224. [CrossRef] 
6. Wahab, S.N.; Ling, E.K. Integrity of Food Supply Chain: Going beyond Food Safety and Food Quality. Int. J. Prod. Qual. Manag. 2019, 1, 216-232. [CrossRef]

7. Spink, J.; Moyer, D.C.; Park, H.; Wu, Y.; Fersht, V.; Shao, B.; Hong, M.; Paek, S.Y.; Edelev, D. Introducing Food Fraud including translation and interpretation to Russian, Korean, and Chinese languages. Food Chem. 2015, 189, 102-107. [CrossRef] [PubMed]

8. Manning, L. Food fraud: Policy and food chain. Curr. Opin. Food Sci. 2016, 10, 16-21. [CrossRef]

9. Spink, J.; Ortega, D.L.; Chen, C.; Wu, F. Food fraud prevention shifts the food risk focus to vulnerability. Trends Food Sci. Technol. 2017, 62, 215-220. [CrossRef]

10. Manning, L. Moving from a compliance-based to an integrity-based organizational climate in the food supply chain. Compr. Rev. Food Sci. Food Saf. 2020, 19, 995-1017. [CrossRef]

11. Wang, C.-S.; Van Fleet, D.D.; Mishra, A.K. Food integrity: A market-based solution. Br. Food J. 2017, 119, 7-19. [CrossRef]

12. Hoorfar, J.; Pruggerl, R.; Butler, F.; Jordan, K. Future trends in food chain integrity. In Food Chain Integrity: A Holistic Approach to Food Traceability, Safety, Quality and Authenticity; Woodhead Publishing Series in Food Science, Technology and Nutrition; Woodhead Publishing Limited: Cambridge, UK, 2011; pp. 303-308. [CrossRef]

13. Elliott, C. Elliott Review into the Integrity and Assurance of Food Supply Networks. Final Report: A National Food Crime Prevention Framework. Crown Copyright. 2014. Available online: https:/ / bit.ly/2NA2CGP (accessed on 14 June 2020).

14. Kleboth, J.; Luning, P.; Fogliano, V. Risk-based integrity audits in the food chain-A framework for complex systems. Trends Food Sci. Technol. 2016, 56, 167-174. [CrossRef]

15. Ali, M.H.; Tan, K.H.; Ismail, D. A supply chain integrity framework for halal food. Br. Food J. 2017, 119, 20-38. [CrossRef]

16. De Boeck, E.; Jacxsens, L.; Bollaerts, M.; Vlerick, P. Food safety climate in food processing organizations: Development and validation of a self-assessment tool. Trends Food Sci. Technol. 2015, 46, 242-251. [CrossRef]

17. Davidson, R.K.; Antunes, W.; Madslien, E.H.; Belenguer, J.; Gerevini, M.; Perez, T.T.; Prugger, R. From food defence to food supply chain integrity. Br. Food J. 2017, 119, 52-66. [CrossRef]

18. Baert, K.; Van Huffel, X.; Wilmart, O.; Jacxsens, L.; Berkvens, D.; Diricks, H.; Huyghebaert, A.; Uyttendaele, M. Measuring the safety of the food chain in Belgium: Development of a barometer. Food Res. Int. 2011, 44, 940-950. [CrossRef]

19. Leitzmann, C. Food Quality: Definition and a holistic view. In Safeguarding Food Quality; Sommer, H., Petersen, B., Wittke, P., Eds.; Springer: Berlin/Heidelberg, Germany, 1993; pp. 3-15.

20. Roth, A.V.; Tsay, A.A.; Pullman, M.E.; Gray, J.V. Unraveling the food supply chain: Strategic insights from China and the 2007 recalls. J. Supply Chain Manag. 2008, 44, 22-39. [CrossRef]

21. Mitenius, N.; Kennedy, S.P.; Busta, F.F. Food Defense (Chapter 35). In Food Safety Management: A Practical Guide for the Food Industry; Academic Press: Oxford, UK, 2014; pp. 937-958.

22. Manning, L.; Soon, J.M. Food Safety, Food Fraud, and Food Defense: A Fast Evolving Literature. J. Food Sci. 2016, 81, R823-R834. [CrossRef]

23. Bogadi, N.P.; Banović, M.; Babić, I. Food defence system in food industry: Perspective of the EU countries. J. Verbr. Lebensm. 2016, 11, 217-226. [CrossRef]

24. Spink, J.; Moyer, D.C. Defining the Public Health Threat of Food Fraud. J. Food Sci. 2011, 76, R157-R163. [CrossRef]

25. Jacobs, D.C. A Pragmatist Approach to Integrity in Business Ethics. J. Manag. Inq. 2004, 13, 215-223. [CrossRef]

26. Schneider, B.; Ehrhart, M.; Macey, W.H. Organizational Climate and Culture. Annu. Rev. Psychol. 2013, 64, 361-388. [CrossRef] [PubMed]

27. Zohar, D. Safety climate: Conceptual and measurement issues. In Handbook of Occupational Health Psychology, 2nd ed.; American Psychological Association: Washington, DC, USA, 2011.

28. Hofmann, D.A.; Morgeson, F.P. Safety-related behavior as a social exchange: The role of perceived organizational support and leader-member exchange. J. Appl. Psychol. 1999, 84, 286-296. [CrossRef]

29. Yiannas, F. Food Safety Culture: Creating a Behavior-Based Food Safety Management System; Springer Science: New York, NY, USA, 2009.

30. Hall, G.B.; Dollard, M.F.; Coward, J. Psychosocial safety climate: Development of the PSC-12. Int. J. Stress Manag. 2010, 17, 353-383. [CrossRef]

31. Griffith, C.; Livesey, K.; Clayton, D. The assessment of food safety culture. Br. Food J. 2010, 112, 439-456. [CrossRef]

32. Griffith, C.; Livesey, K.; Clayton, D. Food safety culture: The evolution of an emerging risk factor? Br. Food J. 2010, 112, 426-438. [CrossRef]

33. Taylor, J. An exploration of food safety culture in a multi-cultural environment: Next steps? Worldw. Hosp. Tour. Themes 2011, 3, 455-466. [CrossRef]

34. Van Achterberg, T.; Huisman-de Waal, G.G.J.; Ketelaar, N.; Oostendorp, R.A.; Jacobs, J.E.; Wollersheim, H.C.H. How to promote healthy behaviours in patients? An overview of evidence for behaviour change techniques. Health Promot. Int. 2011, 26, 148-162. [CrossRef]

35. Zhu, Y.; Akhtar, S. How transformational leadership influences follower helping behavior: The role of trust and prosocial motivation. J. Organ. Behav. 2014, 35, 373-392. [CrossRef]

36. Doyen, B.; Vlerick, P.; Soenens, G.; Vermassen, F.; Van Herzeele, I. Team perception of the radiation safety climate in the hybrid angiography suite: A cross-sectional study. Int. J. Surg. 2020, 77, 48-56. [CrossRef] 
37. Jevšnik, M.; Hlebec, V.; Raspor, P. Food safety knowledge and practices among food handlers in Slovenia. Food Control 2008, 19, 1107-1118. [CrossRef]

38. Ko, W.-H. The relationship among food safety knowledge, attitudes and self-reported HACCP practices in restaurant employees. Food Control 2013, 29, 192-197. [CrossRef]

39. Verhoef, L.; Gutierrez, G.J.; Koopmans, M.; Boxman, I.L. Reported behavior, knowledge and awareness toward the potential for norovirus transmission by food handlers in Dutch catering companies and institutional settings in relation to the prevalence of norovirus. Food Control 2013, 34, 420-427. [CrossRef]

40. Schroevers, M.J.; Sanderman, R.; Van Sonderen, E.; Ranchor, A.V. The evaluation of the Center for Epidemiologic Studies Depression (CES-D) scale: Depressed and Positive Affect in cancer patients and healthy reference subjects. Qual. Life Res. 2000, 9, 1015-1029. [CrossRef]

41. Hinz, A.; Michalski, D.; Schwarz, R.; Herzberg, P.Y. The acquiescence effect in responding to a questionnaire. GMS Psycho Soc. Med. 2007, 4, 1-9.

42. Weijters, B.; Baumgartner, H. Misresponse to Reversed and Negated Items in Surveys: A Review. J. Mark. Res. 2012, 49, 737-747. [CrossRef]

43. López, A.; Sanderman, R.; Smink, A.; Zhang, Y.; Van Sonderen, E.; Ranchor, A.; Schroevers, M.J. A Reconsideration of the Self-Compassion Scale's Total Score: Self-Compassion versus Self-Criticism. PLoS ONE 2015, 10, e0132940. [CrossRef] [PubMed]

44. Kleehammer, K.; Hart, A.L.; Keck, J.F. Nursing Students' Perceptions of Anxiety-Producing Situations in the Clinical Setting. J. Nurs. Educ. 1990, 29, 183-187. [CrossRef] [PubMed]

45. Newell, S.J.; Goldsmith, R.E. The development of a scale to measure perceived corporate credibility. J. Bus. Res. 2001, 52, 235-247. [CrossRef]

46. Rainsbury, E.; Hodges, D.; Burchell, N. Ranking workplace competencies: Student and graduate perceptions. Asia Pac. J. Coop. Educ. 2002, 3, 8-18.

47. Boyle, A.; Maguire, S.; Martin, A.; Milsom, C.; Nash, R.; Rawlinson, S.; Turner, A.; Wurthmann, S.; Conchie, S. Fieldwork is Good: The Student Perception and the Affective Domain. J. Geogr. High. Educ. 2007, 31, 299-317. [CrossRef]

48. Brown, A.V. Students' and Teachers' Perceptions of Effective Foreign Language Teaching: A Comparison of Ideals. Mod. Lang. J. 2009, 93, 46-60. [CrossRef]

49. Robbins, S.P.; Coulter, M. Management, 11th ed.; Pearson Education: Cranbury, NJ, USA, 2012.

50. Koehn, D. Integrity as a Business Asset. J. Bus. Ethics 2005, 58, 125-136. [CrossRef]

51. Becker, T.E. Integrity in organizations: Beyond honesty and conscientiousness. Acad. Manag. Rev. 1998, 23, 154-161. [CrossRef]

52. Guchait, P.; Neal, J.A.; Simons, T. Reducing food safety errors in the United States: Leader behavioral integrity for food safety, error reporting, and error management. Int. J. Hosp. Manag. 2016, 59, 11-18. [CrossRef]

53. Paine, L.S. Managing for organizational integrity. Harv. Bus. Rev. 1994, 72, 106-117.

54. Fassam, L.; Dani, S. A conceptual understanding of criminality and integrity challenges in food supply chains. Br. Food J. 2017, 119, 67-83. [CrossRef]

55. Kessler, S.R. Are the costs worth the benefits? Shared perception and the aggregation of organizational climate ratings. J. Organ. Behav. 2019, 40, 1046-1054. [CrossRef]

56. Leontitsis, A.; Pagge, J. A simulation approach on Cronbach's alpha statistical significance. Math. Comput. Simul. 2007, 73, 336-340. [CrossRef]

57. Jespersen, L.; Maclaurin, T.; Vlerick, P. Development and validation of a scale to capture social desirability in food safety culture. Food Control 2017, 82, 42-47. [CrossRef]

58. Schmitt, N.; Stuits, D.M. Factors Defined by Negatively Keyed Items: The Result of Careless Respondents? Appl. Psychol. Meas. 1985, 9, 367-373. [CrossRef]

59. Baumgartner, H.; Weijters, B.; Pieters, R. Misresponse to Survey Questions: A Conceptual Framework and Empirical Test of the Effects of Reversals, Negations, and Polar Opposite Core Concepts. J. Mark. Res. 2018, 55, 869-883. [CrossRef] 